\section{Commentary: Pump stop and go! But is there a safer way through traffic?}

\author{
Mitesh V. Badiwala, MD, PhD, FRCSC, and \\ Vivek Rao, MD, PhD, FRCSC, FAHA
}

Durable left ventricular assist device (LVAD) support as a "bridge to recoery" leading to LVAD explantation remains the Holy Grail of advanced therapies for heart failure. Although pharmacologic therapy using the Harefield protocol with clenbuterol (a $\beta_{2}$ agonist) resulted in device explant in more than two-thirds of patients, these results have not been widely reproducible. ${ }^{1,2}$ Thankfully, hope is not all lost. The recently reported RESTAGE-HF (Remission from Stage D Heart Failure) trial results suggest that $>50 \%$ of patients with nonischemic cardiomyopathy can undergo successful LVAD explantation after optimization with a standardized pharmacologic regimen using a standard cocktail of widely available heart failure drugs. ${ }^{3}$ As therapies to optimize the conditions for myocardial recovery after LVAD implant are demonstrated to have efficacy, determining which patients should undergo explantation will become critical to achieve success at improving the incidence of device explantation. ${ }^{4}$

Hrytsyna and colleagues ${ }^{5}$ present their experience with using a standardized protocol to predict successful LVAD explantation in this issue of the Journal. They identified 21 of 544 patients $(3.9 \%)$ who successfully proceeded to LVAD explantation with a 95.2\% 1-year survival. Not surprisingly, the patients undergoing explant were younger and

From the Division of Cardiovascular Surgery, Peter Munk Cardiac Centre, Toronto General Hospital, University Health Network; and Department of Surgery, University of Toronto, Toronto, Ontario, Canada.

Disclosures: Dr Rao is a consultant to Medtronic and Abbott and serves on the North American Surgical advisory board to Medtronic. Dr Badiwala has reported no conflicts of interest.

The Journal policy requires editors and reviewers to disclose conflicts of interest and to decline handling or reviewing manuscripts for which they may have a conflict of interest. The editors and reviewers of this article have no conflicts of interest.

Received for publication Jan 21, 2021; revisions received Jan 21, 2021; accepted for publication Jan 25, 2021; available ahead of print Jan 30, 2021.

Address for reprints: Vivek Rao, MD, PhD, FRCSC, FAHA, Division of Cardiovascular Surgery, Peter Munk Cardiac Centre, Toronto General Hospital, University Health Network, Toronto, Ontario, Canada (E-mail: vivek.rao@uhn.ca).

J Thorac Cardiovasc Surg 2022;164:1934-5

$0022-5223 / \$ 36.00$

Copyright (c) 2021 by The American Association for Thoracic Surgery

https://doi.org/10.1016/j.jtcvs.2021.01.095

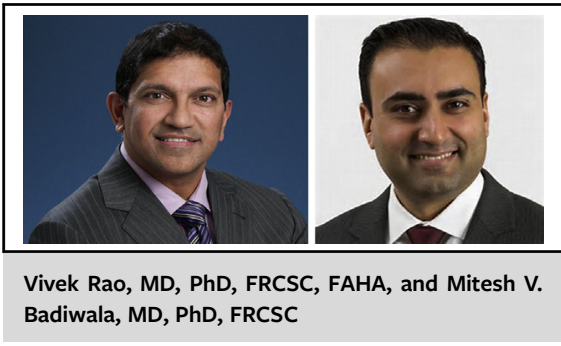

CENTRAL MESSAGE

Assessment of myocardial recovery to select patients for durable LVAD explantation can be performed successfully in a standardized fashion; however, there may be even safer protocols to consider.

had nonischemic cardiomyopathy. Importantly, the authors' standardized protocol used echocardiography under pump stop conditions and subsequent cardiac catheterization with balloon outflow graft occlusion. Both pump stop and balloon graft occlusion are events that raise concern for adverse events, primarily the generation of thromboembolic event or hemodynamic collapse. Neither occurred in any of their patients; however, in 2 cases the pump could not be restarted immediately. Fortunately, both patients tolerated their LVADs not restarting; however, others may not be so fortunate. Although both LVADs in question were identified under a subsequent recall, one cannot assume that future devices will be immune from similar issues, nor will all patients tolerate their pumps not restarting. Furthermore, stopping the LVAD required the presence of a cardiologist, cardiac surgeon, and LVAD engineer, which makes this event resource intensive and may not be feasible in many centers.

We question whether the LVAD needs to be stopped completely as part of the assessment. The authors themselves point out that there were no significant differences in the hemodynamic and echocardiographic measurements during pump stop conditions between those who were ultimately selected for explant and those who were not. One also wonders whether the acute regurgitation that occurs during the pump stop contributed to the reasons for exclusion from consideration for explantation. The hemodynamic changes observed during balloon outflow graft occlusion determined who underwent 
explantation using their protocol. Considering that during continuous-flow LVAD implantation, we start the pump with the outflow graft completely clamped, we believe balloon graft occlusion can be performed with the pump speed turned down to a minimal net flow state. Thus, hemodynamic assessment can be performed with no pump flow but with the pump still spinning and no need to "restart" the pump.

Although the results of this standardized protocol demonstrate that successful LVAD explantation can be performed in a predictable fashion, there may be room for improvement to allow similar protocols to be safely adopted more widely.

\section{References}

1. Birks EJ, Tansley PD, Hardy J, George RS, Bowles CT, Burke M, et al. Left ventricular assist device and drug therapy for the reversal of heart failure. $N$ Engl $J$ Med. 2006;355:1873-84

2. Teuteberg JJ, Cleveland JC, Cowger J, Higgins RS, Goldstein DJ, Keebler M, et al The Society of Thoracic Surgeons Intermacs 2019 annual report: the changing landscape of devices and indications. Ann Thorac Surg. 2020;109:649-60.

3. Birks EJ, Drakos SG, Patel SR, Lowes BD, Selzman CH, Starling RC, et al. Prospective multicenter study of myocardial recovery using left ventricular assist devices (RESTAGE-HF [remission from stage D heart failure]): medium-term and primary end point results. Circulation. 2020;142:2016-28.

4. Phan K, Huo YR, Zhao DF, Yan TD, Tchantchaleishvili V. Ventricular recovery and pump explantation in patients supported by left ventricular assist devices: a systematic review. ASAIO J. 2016;62:219-31.

5. Hrytsyna Y, Kneissler S, Kaufmann F, Müller M, Schoenrath F, Mulzer J, et al Experience with a standardized protocol to predict successful explantation of left ventricular assist devices. J Thorac Cardiovasc Surg. 2022;164:1922-30.e2.
See Article page 1922.

\section{Commentary: The debate continues on optimal myocardial recovery assessment}

\author{
Robert B. Hawkins, MD, MSc, Leora T. Yarboro, MD, \\ and J. Hunter Mehaffey, MD, MSc
}

In their article in the Journal, Dr Hrytsyna and colleagues report their experience with a protocolized method of assessing myocardial recovery with the aim of aggressive left ventricular assist device (LVAD) explantation. ${ }^{1}$ This single-institution retrospective review has 2 helpful characteristics: a large LVAD population (544 patients) and a long-standing protocol-based assessment for explantation, initiated in 2016. After 4 years of using this protocol, 57 patients $(10 \%)$ met the authors' screening criteria and underwent speed manipulation under echocardiographic guidance (including pump stoppage). Of these patients, 37 underwent right heart catheterization-guided pump

\footnotetext{
From the Division of Thoracic and Cardiovascular Surgery, Department of Surgery, University of Virginia, Charlottesville, Va.

Disclosures: The authors reported no conflicts of interest.

The Journal policy requires editors and reviewers to disclose conflicts of interest and to decline handling or reviewing manuscripts for which they may have a conflict of interest. The editors and reviewers of this article have no conflicts of interest.

Received for publication Feb 17, 2021; revisions received Feb 17, 2021; accepted for publication Feb 17, 2021; available ahead of print Feb 22, 2021.

Address for reprints: Robert B. Hawkins, MD, MSc, Division of Thoracic and Cardiovascular Surgery, University of Virginia, PO Box 800679, Charlottesville, VA 22908 (E-mail: rbh6x@virginia.edu).

J Thorac Cardiovasc Surg 2022;164:1935-6

$0022-5223 / \$ 36.00$

Copyright (c) 2021 by The American Association for Thoracic Surgery

https://doi.org/10.1016/j.jtcvs.2021.02.051
}

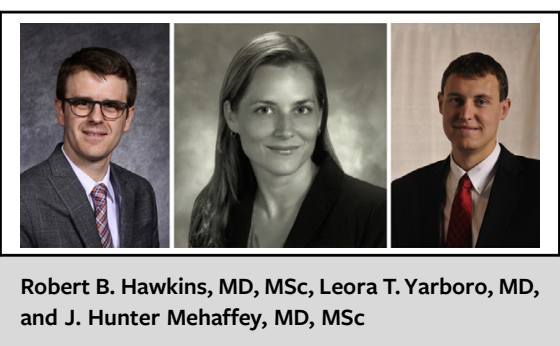

CENTRAL MESSAGE

A standardized and continuous

approach to left ventricular assist

device explantation allows for

safe assessment of myocardial

recovery, although pump stop-

page may provide undue risk and

necessitates further review.

stop with graft occlusion. Finally, 21 patients fulfilled all criteria and were explanted. The rate of $3.9 \%$ is higher than the reported myocardial recovery rates in Europe and North America $(1 \%-2 \%))^{2,3}$ There is no way to truly determine whether this is the optimal protocol and recovery rate, and with only 1 LVAD reimplantation in a noncompliant patient, this protocol ultimately may be too conservative. However, simply developing and then using any protocol increases awareness, screening, and thus, ultimately, explantation.

The authors note a variety of complications, including 3 patients with severe hypotension and 2 patients with pump stoppage malfunctions, one with eventual restart but the 